\title{
Fighting for Equity and Community in an Urban Research University
}

\author{
Mary Ho and George Sanchez
}

\begin{abstract}
The equity lens evaluates institutional barriers that prevent students of color from gaining access to resources for college success (Bensimon, 2005). The first-generation college students at the University of Southern California are $16 \%$ of the total student body and students of color comprise two-thirds of this population. Since 2008, how to support first-generation college students of color in their academic achievement and college success once in college has expanded the discussion beyond access. By evaluating institutional structures through the equity lens, the response has been to create intentional academic and social programs for firstgeneration college students of color that bridge the academic and student services divide. Through descriptions of actual programs and stories from students affected by these programs, this essay will discuss innovative approaches to serving first-generation students of color at predominantly white universities.
\end{abstract}

Keywords: first-generation college students; students of color; equity lens; institutional support; faculty of color

Iris $\mathrm{V}$ entered college a confident, working class Latina who had been an environmental activist in high school. ${ }^{1}$ Iris was a strong student from South Gate High School, a largely Latino high school in southeast Los Angeles County, and she entered the University of Southern California (USC) as a full scholarship student and a Topping Scholar, a competitive scholarship program that provides additional support to first-generation college students. But Iris’ first year was difficult, academically and personally. Struggling in science courses, she began to doubt her own abilities, and most of her courses seemed far removed from the realities of her own urban family and community life. At the end of that first year, Iris was unsure whether USC had been the right choice for her, and she wondered what she was going to be able to do with the disjointed education she was receiving.

The Office for Diversity and Strategic Initiatives (ODSI) of the USC Dornsife College of Letters, Arts \& Sciences oversees programs that generate success for first-generation and underrepresented minority students like Iris. The two authors of this essay ran this office together and established programs that utilized the equity framework developed by Bensimon (2004, 2005) to fully serve this burgeoning population at USC. Although USC is an expensive, private university, it strives to create access for large numbers of first-generation college students. Currently about sixteen percent of USC's eighteen thousand undergraduates are the first in their families to go to college, Twenty one percent are underrepresented minority students, and one out of four are eligible for the Federal Pell Grant program. Initially, most of the efforts were focused on creating access to the university. More recently, the focus has shifted to providing

${ }^{1}$ Psuedonyms are used throughout this essay to refer to actual students described.

Metropolitan Universities Vol. 29 No. 1 (February 2018), DOI: 10.18060/22174 
programs that enable first-generation student of color to succeed, bridging the divide between academic and student services.

The discourse on equity is complex in the higher education setting. Equity in education is focused on creating systems that address unequal education and resources for students of color due to institutional discrimination, racism and bias. The equity framework developed by USC Professor Bensimon is a new paradigm, which moves the conversation away from the deficient framework to analyzing systems that create barriers for students of color (Bensimon, 2005). There are four dimensions in this framework: (a) access, meaning conditions of how students of color gain access to resources, programs, scholarships and services, (b) retention, meaning retention of students of color; (c) institutional receptivity, meaning the scorecard measures of institutional support for students of color; (d) excellence, meaning the integration of access and achievement, to understand how they may prevent students of color from getting the best education possible (Bensimon, 2004, 2005).

In this essay, four such programs developed by USC's ODSI will be featured. A study-abroad program done in partnership with a student service organization for first-generation college students was the first program developed. A course for career planning for first-generation college students enabled a wider group to benefit from reflection and strategies to connect curriculum with career choices. A broader first-generation student task force was created to pull together academic and student service providers from throughout the university to collaborate on best practices and connect with a larger number of students, including a welcoming dinner for newly arrived first-generation students and their families. Finally, a civic engagement model helps first-generation students connect to communities like the ones they come to campus from, and establishes direct connections that bridge academic learning and community networking for student development and advancement.

In the development of all these programs, the input of first-generation students of color was critical in program implementation and revision. Often, Dornsife ODSI was trying to address real issues of educational inequity between students based on race and/or income that led firstgeneration students of color, often low-income, to make certain decisions about their education that did not lead to student success and achievement. ODSI directly promotes equity by fashioning programs that meet this learning gap, but also directly engages students of color in making academic decisions that broaden their outlook on what is possible to achieve academically, personally, and related to their careers after college.

\section{Study Abroad for Equity and Success}

Study abroad would not normally be perceived as an area to promote educational equity because of its costs and limited reach. But at USC, university officials pride themselves on creating global leadership among the student body, and global issues are regularly part of on-campus curriculum discussions. Students from low-income backgrounds who have not travelled before arriving at USC often find themselves left out of these academic discussions, and trying to compete with high-income students were traveling abroad is viewed as commonplace. Because USC often provides resources for low-income students to travel abroad in organized programs, this effort was established in concert with a student scholarship fund and program to promote the 
concept of learning around the globe through travel, reflection and research, connecting the local interests of students with global concerns and problem-solving.

The Norman Topping Student Aid Fund (NTSAF) supports about one hundred students throughout their undergraduate years. Along with the Dornsife ODSI, they partnered to create a high-impact program that would affect Iris' trajectory of achievement for the rest of her undergraduate career. The Japan Summer Immersion Program (SIP) was developed by the Topping Program and the Dornsife ODSI, to give students like Iris an immersive three-week study abroad experience that would capitalize on her student strengths, encourage her to do research, and relate the new experiences of study abroad in Japan with topics more related to experiences that were already familiar to her. In short, this is a program that started with student strengths, not deficits, and capitalizes on USC's commitment to create global leaders that can take on world problems, but explicitly for first-generation students of color that can blossom in a supportive, collaborative experience abroad.

Iris was accepted to this program in her sophomore year and took part in it during the end of that school year in the "Maymester," a time still linked to the spring semester but after final exams when the course can be the student's sole focus. This arrangement was critically important for these low-income students because it did not require additional financial aid for tuition beyond their regular yearly packages. Iris decided to do research on environmental issues in Japan, and both read about Japanese environmentalism and asked questions to Japanese faculty members about issues of pollution and water safety. In her presentation to the group, Iris showed, through photography, how decisions to publicly utilize the rivers that moved through urban Kyoto as areas that could bring families together for leisure activity and reenergize night life, could be contrasted to the lack of use in her native South Gate. There, neglect had allowed environmental pollution of its waterways and kept the largely Latino public from making use of the potential beauty of the nearby river. It was a masterful performance that brought academic confidence back to Iris, and reconnected her to the political and social interests she had before USC. This project helped Iris decide to major in History, Law \& Culture, an interdisciplinary major in Dornsife College, and set her on a path to write a senior honors thesis on the history of environmentalism in South Gate. The Japan SIP also encouraged her to do semester abroad in Brazil as a junior, something that over eighty percent of students who have participated in SIP have also done. Iris is poised to graduate at the end of fall 2017 with honors and go on eventually to law school or graduate school in environmental studies.

The Japan SIP program was established to apply an equity framework to first-generation college students from underrepresented minority backgrounds at USC through high impact practices related to study abroad and research opportunities. When the program was started in 2010, statistics on study abroad participation at USC indicated that first-generation college students were at least twenty percent less likely to participate in traditional study-abroad programs. Because of funding availability for studies abroad in general at USC, and specifically funds available to Norman Topping Scholars, the offices involved knew that this gap was not a result simply of lack of funds by low-income students. Rather there were deeper issues that kept students like Iris from participating in study abroad opportunities in traditional programs. First, the rough start of her academic career at USC meant that a minimum 3.0 GPA requirement often left excellent students from participating in traditional study abroad and research programs, even 
if they were the individual students who might benefit most from these experiences. Secondly, students who came from low-income backgrounds and families in which parents did not go to college shied away from leaving campus for experiences abroad because they did not understand how it might benefit their own academic and career trajectories.

Rather than see these obstacles as deficits in the student's training or desire for studies abroad or research, the Japan SIP program concentrates on the particular experiences and perspectives these students possess that would enhance the overall experience for them. These experiences could be put in service of promoting achievement that would benefit the educational trajectory of students of color for their entire time at USC. It was critically important that the Japan SIP would involve fourteen underrepresented minority undergraduate students who were part of the same fellowship group, along with a team of instructors who were all well-versed on academic success strategies for first-generation college students of color. For most undergraduates selected, this would be the first time they travelled outside the United States or their nation of birth; for some, it would be their very first time on an airplane. Japan was selected as a non-Western nation that had substantial ties to Los Angeles, the home of the University of Southern California, and as a country that was safe to travel for foreigners. For many of the Latina students for whom this was the first time traveling away from home, and especially for their parents, safety concerns were serious issues that kept them from venturing into study abroad. Unlike other programs, we involved the students' parents and families into the planning, by both meeting with them ahead of time so that they could get a taste of what they children would learn and experience, and also setting up a blog so students could post photographs and reflections each day while we travelled abroad. The blog made it easy for family members to follow our progress in Japan, while encouraging many younger siblings of the students to want to pursue college at least in part for the opportunity to study abroad like their older brothers and sisters.

As in Iris' situation, the research component of the Japan SIP was essential for each student to integrate the study-abroad experience with their own academic and personal interests. Almost none of the undergraduates had ever taken an academic course on Japan or East Asia, so it was important for each of them to work on a topic that had salience with their previous interests, and develop a cross-national comparison that would allow them to explore the topic in a region that was new to them. Each of them worked closely with a faculty mentor, often striking up a relationship with a professor that was new around a topic of mutual interest. Furthermore, graduate research assistants helped them focus their research, and develop skills in "research on the go" that would be useful as travel in Japan commenced, including ethnography and interviewing techniques, participant-observation, and photographic documentation. Each student wrote reflections after each day of touring, lectures, and sight-seeing in Japan, and from these initial reflections each was able to craft a research paper and presentation upon their return. For most this was their first research experience. They learned that with attention to detail and their own observations and constant writing, they could craft an analysis that would have interesting things to say about a society that was new to them. Moreover, connecting that research to future courses they could take in their respective majors was a critical component that made the impact long-lasting in their academic maturation.

Japan SIP also broke down barriers between academic and student affairs. Having a critical mass of faculty of color is important in a university. Faculty of color play a vital role in undergraduate 
education because they add value to students and to the university. According to Umbach (2006), faculty of color are more likely to interact with students than their White counterparts, and faculty of color bring a richer experience to the classroom through their contributions of diverse perspectives and pedagogical approaches (Antonio, 2002; Umbach, 2006). Faculty of color also apply more interactive and collaborative teaching with the students and integrate diversity exercises and activities in their courses when compared to White faculty (Umbach, 2006). Although the student body is increasing in diversity over the last 30 years, the faculty of color population has reflected insignificant changes (Antonio, 2002; Umbach, 2006).

Dornsife ODSI operates in an academic unit and was led by a Vice Dean for Diversity, George Sanchez, who is also a full professor in History and American Studies \& Ethnicity. Each of the four Japan SIP trips to date involved Ph.D. students as academic advisors, who helped the undergraduates craft their ideas and provide feedback on their research and writing. This team collaborated with student affairs professionals that knew the students intimately and provided continuity between the Japan SIP course and the life the students led before and after the Maymester experience. The faculty and Ph.D. students are important role models for the students, and connect them with other faculty members upon their return from Japan. Indeed, according to the extensive feedback provided by the undergraduates who have participated in the program, the fact that this collaboration was led by scholars of color and student affairs professionals of color made the instructors more approachable. This aspect allowed undergraduates of color to ask questions they were unlikely to ask of other faculty members, just because of their academic interests.

\section{Unique Pathways to Career Success}

Japan SIP was only the first initiative promoted by Dornsife ODSI to go beyond access approaches to reach low-income, first-generation students of color at USC for student success. First-generation college students are a population that has lately received more attention from the University of Southern California, but the conversation on support for first-generation college students dates back to 2008. Dr. George Sanchez identified first-generation college students as a population on which he had an interest in focusing, when he was appointed in spring 2008 as Vice Dean for Diversity and Strategic Initiatives in USC Dornsife College of Letters, Arts and Sciences.

Initial data collected by the Dornsife ODSI in 2008 indicated that first-generation college students at USC faced unique challenges to succeed that were different than those faced by other USC students and different than those faced by first-generation college students at other colleges and universities. Unlike the situation at other universities, there seemed to be no gap in graduation rates between first-generation college students and those whose parents did attend college. First-generation college students had the same six year graduation rate over ninety percent as other students, and a similar four year graduation rate, close to seventy-five percent. While there was not a "graduation problem" to address, it did seem clear that many firstgeneration college students approached their college graduation without a clear direction of what would come next. Through countless conversations with graduating seniors, Dr. Sanchez and the Dornsife ODSI developed an approach to help first-generation college students better prepare themselves for career success early in the undergraduate years. 
A 2-unit sophomore seminar in "Pathways to Career Success for First Generation College Students," to be taught by Dr. Sanchez, was begun in fall 2013. It was aimed at sophomores and juniors in all majors and all schools who were the first in their families to attend college. Utilizing intense publicity to low-income students through student organizations, transfer student activities, and university offices, combined with a process of clearances before enrollment, the course was limited to students who were the first in their families to attend college. Between forty and fifty students enrolled each time the course was offered each fall semester. The first part of the course was intended to allow students to feel at ease as first-generation college students by discussing initial reactions to USC and its wealth, as well as reading personal accounts of students from similar backgrounds negotiating university life, such as the autobiography of Supreme Court justice Sonia Sotomayor. One group that particularly appreciated this section of the course were transfer students from community colleges in their first or second semester at USC, who were often in shock over the privilege they saw among their classmates and the assumptions of privilege by certain faculty members they had witnessed.

The second half of the course introduced students to services provided at USC for students to explore career options. For students who had worked consistently since they were teenagers, the notion of unpaid internships to advance careers was a foreign, confusing subject. Yet many needed to take unpaid internships to explore the potential careers and to avoid fatal mistakes of planning towards a career that they did not know and would find out they did not enjoy. USC had only nine career counselors at their Office of Career Services, and would often send students to explore options online, but first-generation college students often needed one-on-one counseling about career options and pathways of exploration before they committed. As a result of these discussions, students often changed their majors or made other academic changes to their trajectory because they had not realized that they had more freedom to choose among subjects that they connected to, rather than thinking that there was only one path to obtain financial security through college attendance and graduation.

One of the most challenging issues for many first-generation college students of color was how to balance obligations to families with personal desires for intellectual growth and academic excellence. This class created a "safe space" to discuss these often contradictory impulses for undergraduates trying to plan out their lives. At one level, many students confessed that they were sending substantial portions of their financial aid home to support family finances while they were in college, just like they had with earnings as teenagers to support family economies. Others continued to act as translators for monolingual non-English-speaking parents dealing with landlords or medical professionals, spending as much as time on these actions as they would on a part-time job. Both activities kept students from fully immersing themselves in the high impact practices that would lead to student success in college. The course allowed them to strategize alternative approaches to balancing family obligations with academic commitments and college experiences.

Other balancing acts with family obligations required new commitments to career exploration and discovery. One student who enrolled in the fall 2013 course was Mitzi G, an undergraduate communication student from northern California. Both of Mitzi's parents were undocumented immigrants from Mexico, and Mitzi successfully worked hard to legalize both parents’ status 
while she was an undergraduate student. But Mitzi also returned home each summer to help her father with his gardening business like she had throughout high school. In her major of communication, she realized that summers were often the time when other students were taking advantage of valuable internships to establish themselves in their careers. After a heart-to-heart discussion about her options, Mitzi confessed that her dream was to work for Univision, the Spanish-language media empire affiliated with NBC-Universal. The sophomore seminar course had visits to several employment and internship sites embedded as part of the curriculum, including one to NBC-Universal. Dr. Sanchez encouraged Mitzi to approach them about possible internships at Univision, and talk to her parents about how critical this would be to launch her own investigation into career paths in communications.

Mitzi successfully approached NBC-Universal and was able to secure an internship at Univision the following summer at the end of her sophomore year. Dr. Sanchez had raised funding, which allowed low-income students to take unpaid internships, dedicated for students who take the course. This resource was able to financially allow her to take that initial summer experience. That opportunity led Mitzi to paid internships with other media companies, both big and small, but almost always Spanish language or Latino-oriented organizations or departments. When Mitzi graduated from USC Annenberg School of Communication in 2016, she was offered a coveted position at Facebook, in a new division looking to increase the company's presence among Latino-oriented businesses, both in the United States and in Latin America. Her outward, gregarious personality and her academic success in her courses, coupled with her substantial experiences as an intern for multiple companies put her in a prime position upon graduation for work in her intended field. Success in a field she loved, not just graduation from college, was her goal from the start, and the course was able to get her set up for that pathway.

Mitzi now returns to the course every fall semester to talk to current students about the importance of internships in setting new career pathways for first-generation college students. She explains that internships are one of the few ways that students can learn first-hand about the culture of companies and the skills necessary to be successful in a work setting that requires a college degree. Students listen intently to these real experiences, which often have a greater impact on them than professors or staff encouraging them in the classroom or reading about why high-impact practices are important. Graduates who take the course as undergraduates become a new network of contacts for first-generation college students anxious to meet someone like them, who has used their education for career success.

While the sophomore seminar for career success and the Japan SIP affected a significant set of first-generation college students of color at USC, the Dornsife ODSI also searched for ways to affect the larger culture at USC and reach a greater number of students. This required new networks of faculty and staff professionals, who could collectively affect the culture of the University of Southern California, by emphasizing best practices. Most importantly, the university needed to be pushed to recognize first-generation college students as a population that needed an equity framework, to make the best use of their college education for academic and career success. Moving beyond established ethnic centers and departments of ethnic studies, the First-generation College Student Task Force would be established to organize and publicize best practices for first-generation students at USC, particularly students of color. 


\section{First Generation College Student Summit and Task Force}

The First Generation College Student Task Force was formed in 2013, with the core mission of creating programs and evaluating existing structures through the equity lens. The First Generation College Student Task Force initiatives work to serve all first-generation college students at USC however students of color comprise of two-thirds of the first-generation college students. The total population of first-generation college student is $16 \%$ with transfer students making up one-third of this population. In fall 2016, thirty two percent of first-generation college students were Hispanic/Latino, twenty-one percent were Asian, and six percent were Blackidentified. The intersectionality of being first-generation and being a student of color is complex, due to the student having to carry both identities of being the first in their family to attend college and being a racial/ethnic minority at USC.

Since the formation of the First Generation College Student Task Force in 2013, the initiatives under the Task Force have grown and expanded. Five committees were formed under the Task Force to meet specific programmatic goals and needs:

- Data and Assessment Committee was formed to focus on first-generation college student data, assessment and research in order to developed strategic initiatives addressing issues of access, retention and support for first-generation college students of color.

- The First Generation College Student Parent Programs Committee was formed to develop programs to support parents of first-generation college students.

- The First Generation College Student Summit Planning Committee was formed to plan a summit for students, faculty and staff at USC. The summit reframes the conversation on access and opportunity for first-generation college students through education.

- The First Generation College Student Gathering Committee was formed with the goal of educating faculty and staff about the first-generation college student identity and how their roles at the university can engage and support students who are the first in the families to attend college.

- The task force and committees focus on institutional structures and gaps which prevent first-generation college students of color from academic and college success.

The conversation on excellence for first-generation college students of color, through the lens of the equity framework, is only productive with vital staff partners at the table. Informal initial conversations with staff who themselves identified as first-generation were followed up by formal appointments to university-wide committees that for the first time took first-generation college students as their prime focus. Staff partners from the undergraduate programs office are members of the task force and committees. The conversation around excellence for firstgeneration college students of color generally centered on academic and research opportunities, but started with the very first experience that students had on the day they began at USC on move-in day.

Feedback from first-generation students of color directed the development of several efforts of the Task Force. Students shared that many of their parents were not comfortable on campus, and often did not come onto campus until their student's graduation day. Indeed, parents who did not attend college often dropped their children off on move-in day without attending any event 
sponsored by USC Orientation officials, leaving their children alone in dealing with initial experiences in university housing or first meetings on financial aid or academics. Many firstgeneration college students expressed surprise that other parents were there to help their children with move into the dorms, and asking important questions of university officials, making them feel behind other students even before classes started. So the Task Force decided to begin each year with a welcome dinner for first-generation college families on move-in day, keeping parents on campus and reaching out to each family to celebrate this important day with other parents and undergraduate students experiencing college for the first time.

Beginning in summer 2015, the Task Force sent invitations in multiple languages to families, welcoming them to USC and inviting them to stay for a collective dinner at the end of move-in day. Staff, faculty and advanced undergraduates of color were there in August 2015 to sit at tables with families that had come to drop off their children at college. In addition to a dinner for over 300 individuals, the Provost of the university welcomed these families to the "Trojan family" and a panel of advice for parents was organized by the Task Force, including a firstgeneration faculty member, staff member, undergraduate student, and parent of a USC

undergraduate. New USC parents and families were able to ask this expert panel questions about USC undergraduate life, college academics, and financial aid. Dr. George Sanchez, Dornsife Vice Dean for Diversity, delivered a passionate welcome to the university, stressing the journey of excellence that had gotten their students into USC and celebrating their accomplishments to date.

The importance of this welcome was made clear when the parents of Alejandra F came up to Dr. Sanchez at the end of the 2015 family welcome dinner. Alejandra's family was from Coachella, California, a rural area in the desert about 125 miles outside Los Angeles. Alejandra is the oldest child in the family, with three younger brothers, and she was a star student and valedictorian of Coachella High School. Her parents are both Mexican immigrants who had worked their way up from farm labor. Their border community remains highly differentiated by race and class, with rich desert communities like Palm Desert, sitting next to very low-income communities like Indio and Coachella, dominated by Mexican immigrant families. Attending USC was a dream that Alejandra was able to achieve, and this was the first time her parents had ever stepped on any college campus.

"Senor Sanchez, I want to introduce you to my daughter, Alejandra, who is starting here at USC," said Mr. Franco said in Spanish as they met. "I want to ask you to personally take care of my daughter. Can I entrust her to you?” This sort of introduction and transfer is uncommon for most university deans and faculty. However, it is a common way, a very personal way, that a working-class Latino parent would place responsibility for his blessed daughter in the hands of a university official. "I will do my best to take care of your daughter," answered Dr. Sanchez, knowing that this was a solemn promise. The father then turned to his daughter Alejandra and instructed her to stay in touch with Dr. Sanchez. After a firm handshake between the entire family and Dr. Sanchez, Alejandra said goodbye to her parents, who then drove back three hours to their home base while Alejandra spent her first night in her college dorm.

What resulted from a successful welcome reception for parents of first-generation college students is the creation of the First Generation College Student Parent Committee and an 
institutional partnership with USC Parent and Family Engagement. USC Parent and Family Engagement traditionally caters to legacy families and families of non-first-generation college students. Families who attend the welcome reception can attend Trojan Family Weekend for free. ODSI covers the fee at a discounted rate from Parent and Family Engagement. The partnership with Parent and Family Engagement reframes the conversation on access and inclusivity for parents and families of first-generation college students, particularly parents and families of low-income students.

As a follow-up to her parents' introduction, Alejandra regularly checked in with Dr. Sanchez during her first semester in college, coming in for advice about her classes and discussing her transition to college life at USC. This mentorship situation may have been initiated by Alejandra's father, but it blossomed because both individuals lived up to the promises they had made. In her second semester when she started looking for on-campus employment, Sanchez offered Alejandra a job in Dornsife ODSI, and Alejandra began meaningful employment, working on issues to insure success among diverse undergraduate populations. In her academic work, Alejandra explored several majors, but finally settled on the new Contemporary Latino and Latin American Studies major, an academic program launched through activities by Dornsife ODSI. Because she landed well at USC, Alejandra had a strong academic record after three semesters at USC, so she applied to the Mellon Mays Undergraduate Fellowship Program, a research program aimed at creating new faculty by identifying talented undergraduate researchers. With a strong interview in front of a team of faculty, Alejandra was selected as a MMUF scholar, focusing on research on the cultural transfer in border communities, hoping to apply to Ph.D. programs and eventually become an interdisciplinary faculty member.

Alejandra, supported by her immigrant parents, successfully made the transition to USC in part because the Task Force for First Generation College Students had decided to set up a process by which parents who did not go to college could be introduced to key staff members they could reach out to address their questions and concerns. Later in fall 2015, when USC student leadership had protests over racial tensions on campus-like so many other campuses that semester - these first-generation college students and their parents had contacts they could utilize to address their specific concerns. One of the demands made by students that semester was an increase in faculty of color and greater attention to the needs of students of color by the USC administration. In reaction, the university demanded that each of the nineteen schools at USC establish diversity liaisons, who could listen to the issues of students, faculty, and staff of color and push their respective administrations and USC central administration to respond to these concerns. These school diversity liaisons have become a new set of potential advocates for meeting the needs of first-generation college students of color.

The equity framework assesses conditions of how students of color gain access to resources, programs and scholarships and measures institutional support (Bensimon, 2004; Bensimon, 2005). The equity framework for first-generation college students is applied by educating those who have influence with students and influence at the university. The First Generation Gathering Committee's primary goals are to educate the staff and faculty community on the first-generation college student identity and to have them reflect on how their units or departments may prevent first-generation college students of color from succeeding due to institutional barriers. In fall 2016, the First Generation College Student Gathering Committee worked with the Data and 
Assessment Committee to present data on first-generation college students to the USC diversity liaisons. The diversity liaisons are charged with addressing and meeting the University's diversity goals in their academic schools. The data presentation was paired with a best practice presentation. This new consciousness on the needs of first-generation college students is now taking root throughout the nineteen schools that make up the USC campus.

\section{Civic Engagement Disrupting Traditional Divides}

Another institution that has been established at USC to positively affect success for firstgeneration college students of color is the USC Center for Diversity and Democracy (CDD), also run by Dr. George Sanchez. The CDD was established to combine the issues of diversity in higher education with democratic civic engagement in the communities surrounding the University of Southern California. As a center for civic engagement, the CDD hopes to modernize traditional "town and gown" discussions, which assume that the university "gown" is worn by high income white faculty and students at a research university like USC, while the "town" is not embedded in university cultural life through low-income first-generation college students that come from immigrant and racialized backgrounds, including those from urban communities surrounding the university. As a research center, the CDD hopes to support academic research by faculty and students that directly contributes to the civic engagement literature and public programming that takes into account the growing diversity of student and faculty populations in the university environment and addresses the new American "public", which is often rooted in racialized communities that often do not speak English and are relative newcomers to U.S. society.

Over the past decade, the CDD has engaged in several creative civic engagement projects, each of which centrally involved undergraduates of color who were the first in their families to attend college. In 2010, the CDD celebrated the one hundred year anniversary of the beginning of the Mexican Revolution in Los Angeles, a city where half of its population comes from Mexico, with a friendly competition to write "A Corrido of Los Angeles.” Students from middle and high schools throughout southern California could submit songs they had created through any music genre that celebrated the history and culture of Los Angeles, as long as it told a story in the "corrido" tradition. Over thirty entries were submitted, and a group of university faculty and community partners selected the top ten to perform live with the Grammy-Award winning urban group, Ozomatli. After a powerful and moving rehearsal with the group, students performed their original songs for parents and teachers at the auditorium of the Los Angeles County Museum of Art, which had a related Mexican Revolution exhibition that families could attend.

Another program funded by USC’s Good Neighbors Grant is “History in a Box,” which involved undergraduate researchers developing "boxes” of artifacts and lesson plans for elementary schools in Boyle Heights, a working class Latino neighborhood adjacent to the USC Health Science campus. The CDD partnered with the Breed Street Shul Project to carry out this work, a project of the Jewish Historical Society of Southern California working to restore the most important synagogue in the neighborhood as a community center for the current population. Working with all first-generation college students of color, Dr. Sanchez, with the aid of graduate research assistants, guided undergraduates through research to shape an "immigrant” box that introduced third and fourth graders to the variety of immigrant groups that have made up Boyle 
Heights in the past. The undergraduate researchers place a yarmulke in the box to represent Jewish immigrants, a small bento box to represent Japanese immigrants, and so on, while preparing lesson plans for elementary teachers that allowed them to further explore the history of these groups with their students in class. Teachers in Boyle Heights were so enamored by the boxes and lessons that they asked the "History in a Box" team to develop other boxes that explored science subjects like pollution in the neighborhood or the Los Angeles River, and culture boxes like one that explored the musical diversity among Boyle Heights population in the past.

In the wake of the election of Donald Trump to the U.S. presidency, a candidate that called out Mexican immigrants to the U.S. in derogatory fashion and sought to send many of Boyle Heights residents out of the country, the CDD decided to pursue a new project directly related to teaching the history of Boyle Heights to the local population. The Boyle Heights Museum of History and Culture (BHM) is a project of the CDD in collaboration with CASA 0101, a community-based theater in Boyle Heights founded by Josefina Lopez, the writer and producer of the awardwinning play and movie "Real Women Have Curves." In addition to the current strains in the urban neighborhood, due to the changes in immigration policy brought about by the Trump administration, Boyle Heights is also in the middle of a gentrification process that is putting its local residents at risk of displacement and homelessness. The BHM project hopes to use the history of its own neighborhood to provide guidance for local residents and to teach local history to residents who are often newcomers to the forces that have long been at work in Los Angeles to create disharmony and oppression, as well as the collaborations and coalitions that have fought back for community preservation and empowerment.

USC undergraduate students of color are critical components in the formation of this history museum, and the research they do is central to the public history that is being formed in Boyle Heights. One such student is Kathy $\mathrm{P}$, who joined the group as a freshman student, after beginning at USC from Granada Hills, a suburban neighborhood north of Los Angeles. Kathy is the daughter of two immigrant parents from Ecuador, and her journey to USC has been challenging for a set of reasons that are both unique to her but also representative of the diversity of the urban experience at schools like USC. Before going into her senior year in high school, Kathy institutionalized herself due to severe depression, a result of hiding the fact she was gay from her parents (she also suffered abuse from her partners.) This institutionalization forced Kathy to become a ward of the state, and almost kept the 'A' student from starting her senior year in high school. Because of help from a Latina nurse in the mental institution into which she was assigned, Kathy was able to find the words that got her released, although the courts committed Kathy to LGBTQ therapy with her mother. After she got into USC, Kathy needed to find a supportive community for her burgeoning identity as a Latina lesbian, as well as continued therapy.

Kathy took advantage of Trojan Guardian Scholars (TGS), a program of the Dornsife ODSI for foster care youth, previously homeless students, and those that have been wards of the state. In particular Kathy was able to take advantage of an on-call counselor/mentor, provided by TGS, who was a counselor in training at the USC School of Social Work. Moreover, this put her in touch with Dr. Sanchez, and he eventually became her academic mentor. He first worked with her to change her major from International Relations to Gender Studies and Contemporary 
Latino and Latin American Studies because Kathy expressed an interest in majors that allowed her to continue to explore her complex and emerging identities. Secondly, Kathy explicitly wanted to become a professor, so Dr. Sanchez hired her as his research assistant for his academic work and the BHM project. Kathy applied as the only freshman applicant to the Mellon Mays Undergraduate Fellowship program, and so impressed the faculty selection committee that she was accepted as only the second freshmen in the last twenty years to become a MMUF scholar. Kathy is now working on her individual research on Latina lesbian history in Los Angeles, as well as her work-study job on archival research for the Boyle Heights project.

Institutional programs such as the Trojan Guardian Scholars supports former foster youth by approaching access to resources through an equity lens. The staff coordinator assesses and evaluates the program each year since its launch in 2013, to ensure that barriers preventing scholars from gaining access to resources for college success are removed. The staff coordinator works with a set of staff from vital student support service departments across USC to ensure that their life experiences are integrated when they meet with the scholars.

Recently, Kathy travelled to Washington D.C., along with seven other undergraduates and two graduate students as part of the research team for the BHM project. These students explored Smithsonian and other museums to concentrate on how material objects, photographs, and archival materials become narrative objects for public history. They applied this knowledge to constructing the first exhibition for the Boyle Heights Museum in fall semester 2017 on Mexican repatriation, deportation, and unjust banishment of U.S. citizens of Mexican descent from Boyle Heights during the 1930s. All the students have been doing archival research in the Los Angeles area during 2016-2017, and now translated this work into a public history exhibition. And each of the students involved is Latina/o or African American, from immigrant and working class backgrounds, and also each is a student who wants to make a difference in his/her community by introducing historical research for public consumption.

\section{Conclusion}

The Boyle Heights Museum of History and Culture is a training ground for the next set of professionals that will emerge from USC's first-generation college student community of color. Like the other projects mentioned in this essay, this work at the University of Southern California has prioritized the academic and personal strategies for success among a unique group of undergraduates that represent the future of academia in the twenty-first century. The equity approach, used in all these projects, attempts to respond to the dynamic gifts that these students bring to the campus that both challenge the university's traditional approaches to learning, as well as enhance the setting with new perspectives and trajectories of success. The Japan Summer Immersion Program, the sophomore seminar for "Pathways to Career Success for First Generation College Students,” and the larger initiatives launched the First Generation College Task Force, all work to push an equity agenda at USC. These programs have been largely successful in transforming the lives of current and past low-income undergraduates who are the first in the families to attend college.

Together with faculty, staff and student members of the USC community, these efforts have broadened the atmosphere of inclusion on the campus and led to the institutionalization of 
critical programs for change. The University of Southern California continues to change as attempts to meet the changing needs of a more diverse student body in the twenty-first century, and the Dornsife Office for Diversity and Strategic Initiatives, as well as the USC Center for Diversity and Democracy, have led the way on campus for new, creative ways to meet this challenge. Our philosophy has been to make USC more responsive to being a critical institution for Los Angeles itself, and to become a leading innovator in diverse student programming across the nation for a twenty-first century student body. 


\section{References}

Antonio, A.L. (2002). Faculty of color reconsidered: Reassessing contributions to scholarship. The Journal of Higher Education, 73(5), 582-602.

https://doi.org/10.1080/00221546.2002.11777169

Bensimon, E.M. (2004). The diversity scorecard: A learning approach to institutional change. Change: The Magazine of Higher Learning, 36(1), 44-52

https://doi.org/10.1080/00091380409605083

Bensimon, E.M. (2005). Closing the achievement gap in higher education: An organizational learning perspective. New Directions for Higher Education, 2005(131), 99-111.

https://doi.org/10.1002/he.190

Umbach, P.D. (2006). The contribution of faculty of color to undergraduate education. Research in Higher Education, 47(3), 317-345. https://doi.org/10.1080/00221546.2002.11777169 


\section{Author Information}

Dr. Mary Ho is currently the Assistant Dean for Diversity and Strategic Initiatives in Dornsife College Letters, Arts and Sciences at the University of Southern California. She received her Ed.D in Educational Leadership from the Rossier School of Education at USC in 2016. Her doctoral dissertation was on Chief Diversity Officers and their impact on campus climate. In addition, she received her M.A. in Higher Education Administration in the Steinhardt School of Education, Leadership and Technology from New York University and her B.A. in Political Science from the University of California. In her spare time, she enjoys traveling, running and eating.

* Mary Ho, Ed.D

Dornsife College Office for Diversity and Strategic Initiatives

University of Southern California

3518 Trousdale Parkway

Los Angeles, CA 90089

Telephone: (213)740-4689

Email: maryho@usc.edu

Dr. George Sanchez is Professor of American Studies \& Ethnicity, and History at the University of Southern California, where he also recently served as Vice Dean for Diversity and Strategic Initiatives in the Dornsife College of Letters, Arts \& Sciences. He is the author of Becoming Mexican American: Ethnicity, Culture and Identity in Chicano Los Angeles, 1900-1945 (Oxford University Press, 1993), and co-editor of three other books. Professor Sanchez has served as President of the American Studies Association in 2001-02, chair of the National Advisory Board of "Imagining America: Artists and Scholars in Public Life" from 2007-2011, and President of the Pacific Coast Branch of the American Historical Association in 2015-16. He received the inaugural Equity Award from the American Historical Association in 2011 for an individual who has achieved excellence in recruiting and retaining underrepresented racial and ethnic groups into the historical profession, and was nominated by President Barack Obama to the National Council for the Humanities in 2016. Sanchez received his B.A. in History and Sociology from Harvard University and his Ph.D. in History in 1989 from Stanford University. He was born in Boyle Heights to two immigrant parents from Mexico and was a first-generation college student.

George J. Sanchez

Department of American Studies \& Ethnicity

University of Southern California

3620 S. Vermont Avenue

Kaprielian Hall 462

Los Angeles, CA 90089-2534

Telephone: (213)740-2426

Email: georges@usc.edu

*Corresponding author 